\title{
Endovascular approach of tibial peroneal trunk pseudo-aneurysm
}

\author{
Ana Lorena Abello, MD¹, Víctor Raúl Galvis, MD², William Escobar, MD²

\section{SUMMARY}

This is a case report of a patient with tibioperoneal trunk pseudoaneurysm secondary to firearm injury. Through endovascular intervention, two covered stents were placed on the lesion, with exclusion of the pseudoaneurysm and preservation of the vessel of origin. Arterial Doppler follow up 20 days after intervention revealed adequate stent permeability. In cases of complex extremity trauma with osteo-musculo-vascular involvement, endoluminal repair seems to be a useful tool in distal vessels.

Keywords: Pseudoaneurysm, tibioperoneal trunk, covered stent, endovascular repair, vascular injury, aneurysm.

\section{Reparación endovascular de pseudo-aneurisma del tronco tibioperoneo}

\section{RESUMEN}

Se informa el caso de un paciente con pseudo-aneurisma del tronco tibioperoneo secundario a herida por arma de fuego. Mediante un método endovascular se colocaron dos stents cubiertos en el sitio de la lesión, con exclusión del pseudoaneurisma y preservación del vaso de origen. En el control con doppler arterial a los 20 días de la intervención se evidenció adecuada permeabilidad del stent. En casos complejos de trauma de los miembros, con compromiso ósteo-músculo-vascular, la reparación endovascular parece ser una herramienta útil en los vasos distales.

Palabras clave: Pseudoaneurisma; Tronco tibioperoneo; Stent cubierto; Reparación endovascular; Lesión vascular; Aneurisma.

Few cases of traumatic aneurysms of leg arteries have been reported in literature. The incidence of pseudoaneurysms of the popliteal artery has been estimated in 0 to $3.5 \%$ of all aneurysms found in this artery ${ }^{1}$ and there are approximately 70 cases described ${ }^{2}$, much less frequent is the report of false aneurysms in the popliteal artery branches.

Using endovascular therapy is an important resource in these types of lesions, given that it is a less invasive procedure, with lowered bleeding, minor complications of the surgical wound, shorter hospitalization, and faster recovery in comparison to surgery. Additionally, this procedure is currently easily available in our region.

In 1994, Gerermia et al. ${ }^{3}$ used intravascular stents in pseudoaneurysms created experimentally on the wall of a vessel in dogs, inducing aneurismal sac thrombosis, while maintaining the vessel permeable. That same year, Marks et al. ${ }^{4}$ published two of pseudoaneurysms in humans who were successfully treated with intravascular stents. Herein, we report a case of a patient with tibioperoneal trunk pseudoaneurysm who was intervened with covered stents.

\section{CASE REPORT}

A 32-year-old patient is admitted to Hospital Universitario del Valle (Cali, Colombia) with a firearm injury with entry wound in the distal third and medial region of the right thigh and exit wound in the lateral aspect of the upper third of the leg. The patient has a fractured fibula and vascular lesion is suspected on the vascular route (in spite of not presenting signs of distal ischemia).

1. Resident, Section of Radiology, Department of Internal Medicine, School of Medicine, Universidad del Valle, Cali, Colombia.e-mail: anaabellop@hotmail.com

2. Professor, Section of Radiology, Department of Internal Medicine, School of Medicine, Universidad del Valle, Cali, Colombia. e-mail: vigalvis@ hotmail.com wescobar@imbanaco.com.co

Received for publication July 15, 2008 Accepted for publication May 11, 2010 


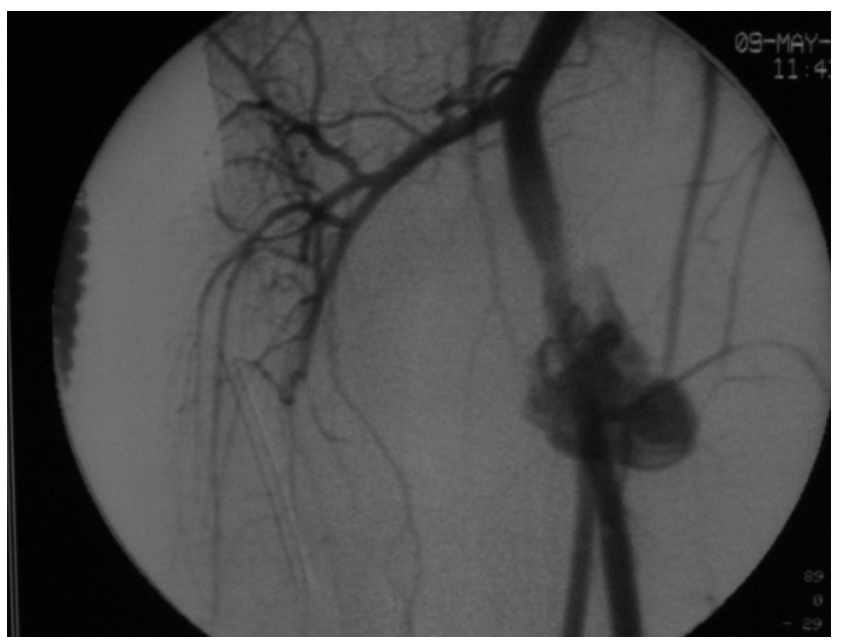

Figure 1. Digital subtraction angiography. Right tibioperoneal trunk pseudoaneurysm and occlusion of the anterior tibial artery

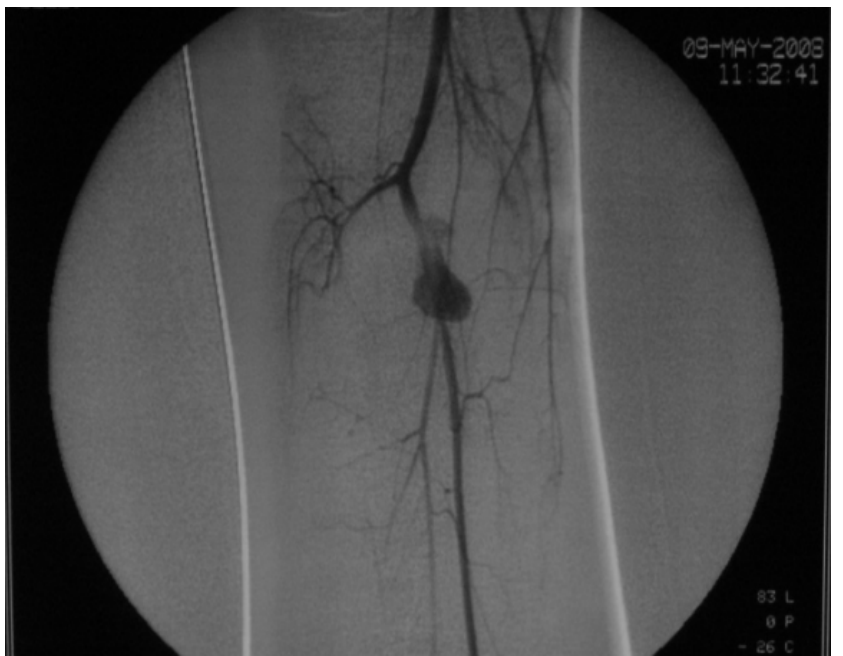

Figure 2. Digital subtraction angiography. The anterior tibial artery was occluded a few centimeters from its emergence. The peroneal and tibial arteries are then noted thinned

The patient was taken to the hemodynamics ward where angiography is performed with digital subtraction, evidencing a 35 x $24 \mathrm{~mm}$ tibioperoneal trunk pseudoaneurysm at the middle third junction with the distal and occlusion of the anterior tibial artery (Figures 1,2).

Endovascular repair was decided upon with prior premedication with clopidogrel $300 \mathrm{mg}$ load followed by $75 \mathrm{mg} /$ day and aspirin ( $100 \mathrm{mg}$ /day) five days before the procedure. Also, the informed consent form is filled out and signed by the patient.

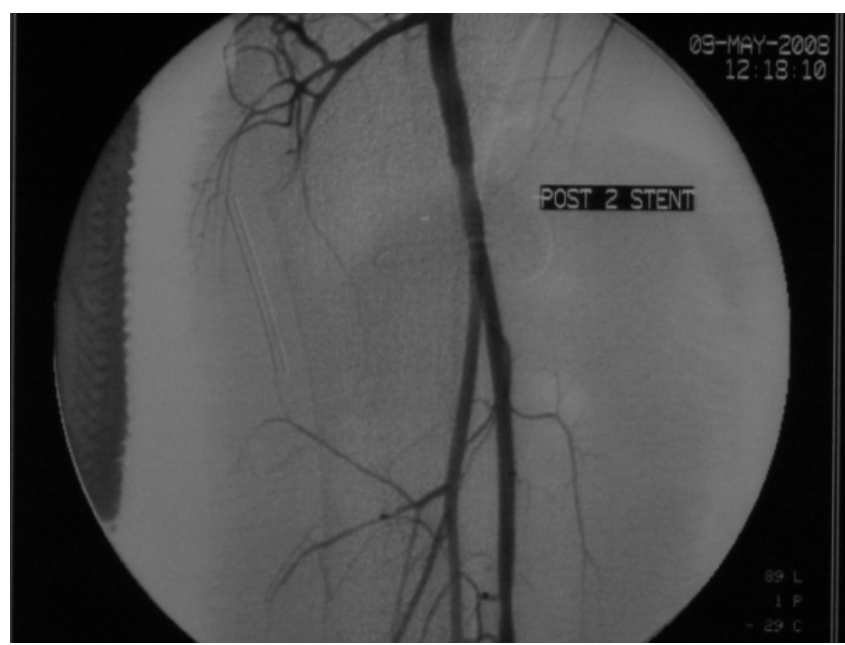

Figure 3. After the implants of two covered stents on the lesion site, note total exclusion of the pseudoaneurysm and preservation of the artery of origin and the tibioperoneal trunk branches. The distal flow also shows improvement

The right common femoral artery was punctured in anterograde manner with 7Fr introducer (Boston Scientific, Nathan Lane, Plymouth, USA). Thereafter, the posterior tibial artery was catheterized distal to the pseudoaneurysm with a $185 \mathrm{~cm} 0.014 \mathrm{PT}^{2} \mathrm{MS}$ micro guide (Boston Scientific Nathan Lane Plymouth, USA), and through it, two $(3.5 \times 16 \mathrm{~mm}$ and $5 \times 19 \mathrm{~mm})$ PTFEcovered stents were released (Jostent GraftMaster, Abbott Park, Illinois, USA), covering the pseudoaneurysm and excluding it from the circulation (Figure 3).

Rigorous follow up will be made of stent permeability with arterial Doppler every two months and with CT angiotomography every six months to determine the long-term results of the intervention.

\section{DISCUSSION}

In an exhaustive literature review combining the words tibioperoneal trunk, pseudoaneurysm, false aneurysm, and stent we only found reports of cases of patients with pseudoaneurysms of arteries of the leg and almost all were intervened with surgery. One of these reported tibioperoneal trunk pseudoaneurysm associated to Behçet's disease, which was diagnosed via Doppler and CT angiotomography ${ }^{5}$. Another article retrospectively gathered accounts of pseudoaneurysms of the 
popliteal artery and tibioperoneal arteries reporting two lesions of the posterior tibial artery, pseudoaneurysm of the anterior tibial, and peroneal pseudoaneurysm. In this last study, the approach taken to treat all the traumatic aneurysms was surgical: vein graft insertion, terminoterminal anastomosis, lateral suture and ligation, with $66.6 \%$ complications among which venous thrombosis, graft occlusion, and wound infection were the most frequent ${ }^{6}$.

May et al. ${ }^{7}$ reported six cases of pseudoaneurysms in different parts of the body (none in arteries of the leg) that were intervened via endovascular therapy with good results, concluding that endoluminal management of these types of lesions was a valid option and avoided the morbidity associated to open surgery.

McKee et al. ${ }^{8}$ reported a case of a patient with mycotic aneurysms of the posterior bilateral tibial arteries and of the right peroneal artery secondary to bacterial endocarditis, which were intervened via saphenous vein grafts and antibiotic therapy.

True aneurysms of the tibioperoneal trunk and of the other infrapopliteal vessels are even less frequent and most reports state that surgical intervention has been the treatment approach with interposition of venous graft ${ }^{9,10}$.

Del Grande et al. ${ }^{11}$ reported embolization by direct puncture of a pseudoaneurysm as complications during embolectomy with the Fogarty balloon catheter, which saved the patient's extremity.

In our patient we used two superimposed stents that covered the lesion at the tibioperoneal trunk and after their implantation, total exclusion of the pseudoaneurysm was shown with improved flow of the posterior tibial and peroneal arteries. During a follow up with arterial Doppler twenty days after the procedure, stent permeability was noted along with adequate distal circulation.

While it may be true that in peripheral arteries susceptible to compression and tensile and bending forces, expandable balloon stents (as in this case) may deform and have a greater probability of stenosis, it is worth bearing in mind the innovations this field has seen in recent years like, for example, the implementation of the Hemobhan Stent Graft; a device with a special structure that minimizes risk of kinking with flexion movements ${ }^{12}$. With these types of stents, Tielliu et al. ${ }^{13}$ and Gerasimidis et al. ${ }^{14}$ have demonstrated adequate short-term permeability with primary permeability rates of $75 \%$ at 15 months in the first and secondary permeability of $75 \%$ at 12 months in the latter; both in treatments for popliteal artery aneurysms.

On the other hand, studies evaluating the infrapopliteal endovascular therapy in managing occlusive arterial disease have yielded insufficient data, when compared to bypass surgery and future studies are suggested to establish its real role ${ }^{15}$. In recent years, sirolimus-eluting stents have been placed to treat infrapopliteal stenosis, revealing promising results by inhibiting restenosis and diminishing recurrent ischemia of the lower limbs and repeated procedures of revascularization ${ }^{16}$.

It is possible that when dealing with patients with traumatism of the extremities, endovascular therapy for treatment of pseudoaneurysms or arteriovenous fistulas may show better results than those obtained till now with the treatment for occlusive arterial disease, bearing in mind that in our environment most patients with these types of injuries are young patients with relatively healthy endothelium in whom lower long-term probability of occlusion is expected. Further studies are necessary with sufficient samples to corroborate this hypothesis.

In spite of the limitations discussed, in this patient, the insertion of two covered stents was a valid option given that it reestablished vessel permeability and avoided greater morbidity associated to the surgery. Long-term follow up with Doppler and CT angiography will determine the need for surgical intervention.

In conclusion, we consider it feasible to conduct endovascular intervention of traumatic aneurysms of infrapopliteal arteries, with adequate follow up and, whenever possible, using the best technology given that no hard evidence is available of the best treatment option.

\section{REFERENCES}

1. Gillespie DL, Santelmo NL. Traumatic popliteal artery pseudoaneurysms: Case report and review of the literature. $J$ Trauma. 1991; 31: 412-5.

2. Megalopoulos A, Siminas S, Trelopoulos G. Traumatic pseudoanerysm of the popliteal artery alter blue trauma: case report and review of the literatura. Vasc Endovascular Surg. 2007; 40: 499-504 .

3. Geremia G, Haklin M, Brennecke L. Embolization of experimentally created aneurysms with intravascular stent devices. AJNR Am J Neuroradiol. 1994; 15: 1223-31.

4. Marks MP, Drake MD, Steinberg GK, Norbash AM, Lane B. Stent placement for arterial and venous cerebrovascular disease: preliminary experience. Radiology. 1994; 191: 441-4. 
5. Tizniti S, Hammani L, Imani F. Faux anévrisme sural révélateur d'une maladie de Behçet. Editions Fançaises de Radiologie. 2001; 82: 1013-5.

6. Ozisik K, Dural K, Okcu O, Han S, Yildirim E, Sakinci U. Pseudoaneurysms of the popliteal and tibioperoneal arteries after gunshot injuries. J Trauma Inj Infect Crit Care. 2003; 55: 485-88.

7. May J, White GH, Yu W, Waugh R, Stephen MS, Harris JP. Endoluminal repair: a better option for the treatment of complex false aneurysms. Aust NZJ Surg. 1998; 68: 29-34.

8. McKee MA, Ballard JL. Mycotic aneurysms of the tibioiperoneal arteries. Ann Vasc Surg. 1999; 13: 188-90.

9. Cappendijk VC, Mouthaan PJ. A true aneurysm of the tibioperoneal trunk. Case report and literature review. Eur J Vasc Endovasc Surg. 1999; 18: 536-7.

10. Mönig SP, Michael W, Sorgatz S, Erasmi H. True infrapopliteal artery aneurysm of two cases and literature review. J Vasc Surg. 1996; 24: 276-8.

11. Del Grande F, Cassina P, Leu A, Pfammatter T. Repair of infrapopliteal postembolctomy complications with variant embolization techniques. Cardiovasc Intervent Radiol. 2001; 24: 280-2.

12. Antonello M, Frigatti $P$, Battocchio $P$, Lepidi S, Cognolato D, Dall'Antonia A, et al. Open repair versus endovascular treatment for asymptomatic popliteal artery aneurysm: Results of a prospective randomized study. J Vasc Surg. 2005; 42: 185-93.

13. Tielliu IF, Verhoeven EL, Prins TR, Post WJ, Hulsebos RG, van den Dungen JJ. Treatment of popliteal artery aneurysms with the Hemobahn stent-graft. J Endovasc Ther. 2003; 10: 111-6.

14. Gerasimidis T, Sfyroeras G, Papazoglou K, Trellopoulos G, Ntinas A, Karamanos D. Endovascular treatment of popliteal artery aneurysms. Eur J Vasc Endovasc Surg. 2003; 26: 50611.

15. Romiti M, Albers M, Brochado-Neto FC, Durazzo AE, Pereira CA, De Luccia N. Meta-analysis of infrapopliteal angioplasty for chronic critical limb ischemia. J Vasc Surg. 2008; 47: 97581.

16. Karnabatidis D. Infrapopliteal stents: overview and unresolved issues. J Endovasc Ther. 2009; 16 (Suppl 1): 153-62. 